\title{
Retrieval and phenomenology of autobiographical memories in blind individuals
}

\author{
Ali İ. Tekcan, Engin Yılmaz, Burcu Kaya Kızılöz, Dilay Z. Karadöller, \\ Merve Mutafoğlu, and Aslı Aktan Erciyes
}

Department of Psychology, Boğaziçi University, İstanbul, Turkey

(Received 13 August 2013; accepted 20 January 2014)

\begin{abstract}
Although visual imagery is argued to be an essential component of autobiographical memory, there have been surprisingly few studies on autobiographical memory processes in blind individuals, who have had no or limited visual input. The purpose of the present study was to investigate how blindness affects retrieval and phenomenology of autobiographical memories. We asked 48 congenital/early blind and 48 sighted participants to recall autobiographical memories in response to six cue words, and to fill out the Autobiographical Memory Questionnaire measuring a number of variables including imagery, belief and recollective experience associated with each memory. Blind participants retrieved fewer memories and reported higher auditory imagery at retrieval than sighted participants. Moreover, within the blind group, participants with total blindness reported higher auditory imagery than those with some light perception. Blind participants also assigned higher importance, belief and recollection ratings to their memories than sighted participants. Importantly, these group differences remained the same for recent as well as childhood memories.
\end{abstract}

Keywords: Autobiographical memory; Visual imagery; Memory phenomenology; Visual impairment; Blindness.

Visual imagery is considered an integral part of autobiographical remembering (Brewer, 1996; Conway, 2005; Conway \& Pleydell-Pearce, 2000; Rubin, 1995). In his autobiographical memory model, Conway (2005) suggests that autobiographical memories contain a summary of sensory and perceptual processing, and "are predominantly represented in the form of (visual) images" (p. 613). Empirically, several studies with sighted individuals showed that visual imagery is almost always present when one recollects episodes from one's past (e.g., Brewer, 1986; Rubin \& Kozin,
1984). For instance, Rubin and Kozin (1984) asked participants to rate autobiographical memories in terms of vividness by asking "How vivid is your memory of this event?" (1 corresponding to "no image at all" and 7 equivalent to "as vivid as normal vision"). They found that none of the memories were given a rating of 1 , whereas approximately $75 \%$ of the memories were given a rating of 5 or higher, and $30 \%$ were given a rating of 7. Although present (e.g., Eardley \& Pring, 2006), imagery in other modalities (e.g., auditory, olfactory, etc.) seems to be less common

Address correspondence to: Ali İ. Tekcan, Department of Psychology, Boğaziçi University, Bebek 34342, İstanbul, Turkey. E-mail: ali.tekcan@boun.edu.tr

A portion of the data was collected as part of the E.Y.'s master's thesis under the supervision of A.İ.T. at Boğaziçi University. Initial stages of data analyses and writing were done when A.İ.T. was a visiting researcher at Aarhus University, Center of Autobiographical Memory Research (CON AMORE) in 2010. He gratefully acknowledges the hospitality of all the members of the centre as well as their feedback on earlier versions of this work. We also would like to thank David C. Rubin and an anonymous reviewer for their comments and suggestions. 
components of autobiographical remembering (Williams, Healy, \& Ellis, 1999).

Visual imagery is also shown to be related to the sense of recollection, a defining characteristic of autobiographical remembering (Brewer, 1996). For instance, Rubin, Schrauf, and Greenberg (2003) found that measures of recollective experience (i.e., sense of reliving the original events and mentally travelling back in time) had the highest correlations with ratings of visual imagery. The link between visual imagery and autobiographical memory has been supported by neurophysiological studies, showing higher activation in occipital regions especially during elaboration of retrieved autobiographical memories (e.g., Conway, Pleydell-Pearce, \& Whitecross, 2001; Conway, Pleydell-Pearce, Whitecross, \& Sharpe, 2003; Svoboda, McKinnon, \& Levine, 2006). There is also evidence that damage to visual cortex leads to symptoms of retrograde and anterograde amnesia (Rubin et al., 2003).

One way of addressing the link between visual imagery/system and autobiographical memory is to investigate how blindness affects memory. Studies looking at memory in cortically caused blindness reported substantial retrograde and anterograde amnesia (e.g., Greenberg, Eacott, Brechin, \& Rubin, 2005; Greenberg \& Rubin, 2003; Ogden, 1993; Rubin \& Greenberg, 1998). Rubin and Greenberg (1998) reviewed cases of 11 patients with long-term visual memory loss and found that all of these patients had amnesia (with a stronger retrograde than anterograde component), leading them to argue that these patients show evidence for a new form of amnesia they called "visual-memory-deficit amnesia" (VMDA). There is also evidence that such patients not only recall fewer memories in response to cue words, but also report lower ratings on visual and spatial imageries (Greenberg et al., 2005).

In terms of research with blind individuals who lost their sight due to non-cortical causes, a large body of work addressed imagery and working memory (especially regarding visuo-spatial domain) or long-term episodic memory for word lists (e.g., Saariluoma \& Kalakoski, 1998; Vecchi, 1998). However, there are surprisingly few studies on autobiographical memory, which is intriguing, given the significant role attributed to visual imagery in remembering one's past experiences (e.g., Brewer, 1986, 1996).

The few existing studies report data on retrieval success as well as the types of imagery associated with autobiographical memories. In terms of retrieval success, the evidence is somewhat mixed. Goddard and Pring (2001) tested the autobiographical memory performance of blind children and adolescents. They suggested that blind participants were able to retrieve specific autobiographical memories at the same level as the normal controls, but with much less detail and after substantial prompting. They, however, did not collect any comparison data from normal control participants and only had eight blind participants in the study. Therefore, the results should be cautiously interpreted. In a study with adults, Eardley and Pring (2006) found that blind participants retrieved fewer specific memories in response to cue words. Moreover, this was true for abstract (e.g., greed), visual (e.g., sunset) and auditory (e.g., thunder) words. Interestingly, however, within the blind group, nature of the words did not make a difference. Additionally, Pring and Goddard (2004) examined autobiographical memory in blind and sighted adults by using semistructured interview and cue word techniques. They found no difference in retrieval speed or retrieval success between the groups, although there was a tendency for the blind group to retrieve fewer memories than the sighted group when elicited by cue words ( $83 \%$ vs. $92 \%)$. There was also no group difference on vividness of memories reported in the semi-structured interview.

Autobiographical memories contain multimodal imagery (Conway, 2005; Rubin, 2005, 2006), and vision undoubtedly plays an important role in establishing episodic memories; through vision, people are able to instantly encode and integrate large amounts of information. As such, autobiographical memories of blind individuals need to be formed, integrated, rehearsed and retrieved without the benefit of visual input. To the degree that visual input plays a role in these autobiographical memory processes, some decline in congenitally blind individuals might be expected. Congenitally blind individuals need to develop some compensatory strategies in the formation as well as the retrieval of those memories. Recollective experience, the sense of remembering a memory, for instance, should now be based on alternative imagery components and their interactions. There is evidence of such compensation at the behavioural as well as neurological level. Blind participants perform better in auditory or tactile perception tasks (Alary et al., 2009; Lessard, Pare, Lepore, \& Lassonde, 1998; Postma, Zuidhoek, Noordzij, \& Kappers, 2007; 
Rokem \& Ahissar, 2009; Röder, Rösler, \& Spence, 2004; Tinti, Galati, Vecchio, De Beni, \& Cornoldi, 1999). There is also evidence of cortical reorganisation following congenital or early-onset blindness in that occipital cortex is recruited for other sensory functions (Amedi, Raz, Pianka, Malach, \& Zohary, 2003; Thaler, Arnott, \& Goodale, 2011) as well as higher functions such as memory (Pasqualotto, Lam, \& Proulx, 2013; Raz, Amedi, \& Zohary, 2005).

Compensation is also evident in terms of imagery associated with autobiographical memory. Ogden and Barker (2001) compared the dominant modalities in autobiographical memories of sighted, early-blind (before 2 years of age) and late-blind (after 8 years of age) participants. They asked participants to remember certain early experiences (e.g., "Describe the first school you ever went to") and recent experiences (e.g., "Describe a party, gathering or major event that you have attended in the last few months"). The most common imagery modality in descriptions of childhood memory narratives was visual (followed by spatial) for sighted individuals, whereas for early-blind group, there was no visual imagery reported; spatial imagery was the most common, followed by tactile and auditory modalities. For recent memories, sighted participants' recollections heavily referred to visual imagery, with minimal reference to remaining modalities. For the early-blind group, the most common modality was again spatial followed by auditory and tactile modalities. For the late-blind group, there was minimal reference to visual imagery; auditory tactile and spatial imagery were referred equally likely (between $20 \%$ and $30 \%$ ).

Ogden and Barker (2001) emphasised the unexpected predominance of spatial modality for all groups for childhood memories and for the two blind groups (early- and late-blind) for recent memories. Another important point was that loss of visual imagery seemed to be compensated by imagery in other modalities: auditory and tactile modalities became more dominant, while spatial imagery remained relatively unchanged. These findings suggest a direct correspondence between the visual input and the imagery at retrieval. It has to be noted, however, that most of the questions used in this study did not refer to specific autobiographical experiences but rather more general descriptions of locations and people.

An experimental study by Rubin, Burt, and Fifield (2003) provides relevant data. Participants took part in a discussion group while they were blindfolded. Ten days later and not-blindfolded, they recollected the event and rated several aspects of their memory (recollection, belief, imagery, etc.). Having been blindfolded lowered ratings of visual and spatial imagery at retrieval. Limiting visual input at encoding by blindfolding also decreased ratings of recollection and belief. These findings suggest that a lack of visual input at encoding has a direct effect on the imagery and recollection reported at retrieval. Given that the participants were sighted and relied on sight all their lives, it is reasonable that there was no evidence of compensation.

\section{THE PRESENT STUDY}

The main objective of the present study was to investigate how ocular (non-cortical) blindness affects retrieval and phenomenology of autobiographical memories. In terms of phenomenology, we went beyond simply investigating types of imagery and measured other variables such as importance and rehearsal. We also collected measures of recollective experience of the event as well as belief in the accuracy of memories. Within that context, we were guided by the basic systems approach to autobiographical memory (Rubin, 2006; Rubin et al., 2003), which argues that autobiographical memories are products of component processes such as imagery in different modalities, language, narrative structure and emotions. There is substantial empirical evidence showing that these components have neurological and behavioural separability and plausibility (Greenberg \& Rubin, 2003; Rubin, 2005, 2006).

According to this formulation, recollection and belief, two metacognitive judgments about one's sense of remembering, are essential components of retrieving and reporting autobiographical experiences. The subjective sense of recollection is considered as a definitive characteristic of autobiographical memory and functions to separate autobiographical memory from autobiographical facts as well as real memory from dreaming, etc. (Rubin et al., 2003). Belief refers to one's belief in the accuracy of what is remembered (i.e., the degree to which the individual believes that what is remembered has actually happened, and is not a product of imagination).

We measured these properties with the Autobiographical Memory Questionnaire (AMQ; Rubin et al., 2003), which has been used in several studies (Ely \& Mercurio, 2011; Greenberg et al., 2005; 
Rubin, Boals, \& Berntsen, 2008; Rubin \& Siegler, 2004; Sheen, Kemp, \& Rubin, 2001; Talarico, LaBar, \& Rubin, 2004), including Turkish samples (Rubin, Schrauf, Gulgoz, \& Naka, 2007).

In short, our overall goal was to address whether and how sighted and blind individuals would differ in their retrieval and phenomenology of specific autobiographical memories. In addition, we also addressed the effects of age of memory on these differences.

\section{METHOD}

\section{Participants}

Forty-eight blind (23 women, 25 men) and 48 sighted ( 24 women, 24 men) adults participated in this study. Of the blind participants, 34 were congenitally blind, and 14 had lost their sight within the first year of their lives. Within the blind group, 16 had total loss of sight (no light perception) and 24 had light sensitivity but no pattern perception. Sight level data were missing for eight of the blind participants.

Blind participants were slightly older $(M=$ $26.38, S D=4.91)$ than sighted participants $(M=$ 24.21, $S D=5.61), t(94)=2.02, p=.046$. There was no difference in years of education between blind $(M=12.90, S D=3.25)$ and sighted participants $(M=13.75, S D=2.89), t(86)=1.30, p=.57$. Blind and sighted participants were either undergraduate students taking psychology classes at Boğaziçi University or older adult volunteers. The student participants were given extra credits for their participation.

\section{Materials}

Cue words. A total of nine cue words were used: glass, ship, pillow, soup, tree, bell, carpet, newspaper and strawberry. All the words were mediumto-high frequency concrete words in Turkish (Göz, 2003). The first six words comprised the standard list used for all participants, and the last three were used as substitutes when the participants were unable to produce a memory in response to first six words (for details see the Procedure).

Autobiographical Memory Questionnaire. The AMQ (Rubin et al., 2003) consists of statements about phenomenological properties of memories. The AMQ items used in the present study are
TABLE 1

Variables and the statements used to measure them in the AMQ

\begin{tabular}{ll}
\hline Variables & \multicolumn{1}{c}{ Statement } \\
$\begin{array}{l}\text { Metacognitive judgments } \\
\text { Reliving }\end{array}$ & $\begin{array}{l}\text { I feel as though I am reliving the } \\
\text { original event } \\
\text { I feel that I travel back to the time it } \\
\text { happened }\end{array}$ \\
Remember/Know & $\begin{array}{l}\text { I can actually remember it rather } \\
\text { than just knowing that it happened }\end{array}$ \\
Real/Imagine & $\begin{array}{l}\text { I believe the event in my memory } \\
\text { really occurred in the way I } \\
\text { remember it }\end{array}$ \\
$\begin{array}{ll}\text { Component processes } \\
\text { See }\end{array}$ & $\begin{array}{l}\text { I can see it in my mind } \\
\text { I can recall the setting where it } \\
\text { occurred }\end{array}$ \\
I can hear it in my mind \\
Talk & $\begin{array}{l}\text { I or other people are talking } \\
\text { I can feel now the emotions I } \\
\text { felt then }\end{array}$ \\
It comes to me as a coherent story & This memory is significant for \\
Story & my life \\
Seported properties & talked about this event \\
Importance & $\begin{array}{l}\text { Date of the memory (month/ } \\
\text { day/year) }\end{array}$ \\
Rehearsal & \\
Age of event & \\
\hline &
\end{tabular}

presented in Table 1. The statements in AMQ refer to three classes of variables, and each statement is rated on a 7-point scale.

Metacognitive judgments. The two metacognitive variables, recollection and belief, were each measured by two variables. Recollection was measured by Reliving and Back in time, whereas belief was measured by Remember/Know and Real/Imagine statements. Although Remember/Know distinction has sometimes been considered a measure of recollection, Rubin and colleagues (e.g., Rubin et al., 2003) showed that it is more closely associated with belief rather than recollection.

For Reliving and Back in time, the scale ranged from "not at all" to "as clearly as if the event was happening now". For Remember/Know, the scale ranged from "not at all" to "extremely clearly", with higher ratings indicating stronger remember experience. For Real/Imagine, the scale ranged from " $100 \%$ imaginary" to " $100 \%$ real".

Component processes. Statements about the component processes contained visual imagery 
(See), auditory imagery (Hear), spatial imagery (Setting), language (Talk), emotion (Feel) and narrative (Story). For all these variables, the scale ranged from "not at all" to "as clearly as if the event were happening now".

Reported properties. Participants rated the importance (from "not at all" to "extremely important") and rehearsal frequency of the event (from "not at all" to "one of the most frequently rehearsed/talked events in my life"). They were also asked to report their age at the time of the event in the memory.

\section{Procedure}

All participants were interviewed individually. All interviews were tape-recorded. At the beginning of the session, participants were informed that they would be presented with cue words and they should try to report the first autobiographical memory that each word reminds them. They were also informed that memories should be specific events that happened in a particular context and within a short period of time, extending not more than a few hours.

Each word was presented to the participants, and after the participant provided a memory, s/he was asked to respond to the questions on the AMQ. This was repeated for all six words. The order of presentation for words was fixed. If the participants were unable to report a memory for a word for three minutes, the experimenter moved on to the next word. The word(s) for which participants failed to report a memory was/were presented again after the presentation of the sixth word. If the participant did not report any memories this time as well, the experimenter moved on to presenting substitute words.

\section{RESULTS}

\section{Retrieval performance}

The proportion of memories reported by the two groups was compared. Sighted participants were more successful in retrieving memories $(96.15 \%)$ than blind participants $(82.69 \%), z=2.23$, $p=.026$.

All the following analyses are based on the average ratings of all memories reported by each
TABLE 2

Means, standard deviations, $t$-test results and effects sizes for variables in $\mathrm{AMQ}$

\begin{tabular}{|c|c|c|c|c|c|c|}
\hline \multirow[b]{2}{*}{ Variables } & \multicolumn{2}{|c|}{ Blind } & \multicolumn{2}{|c|}{ Sighted } & \multirow[b]{2}{*}{$t$} & \multirow[b]{2}{*}{$\eta^{2}$} \\
\hline & Mean & $S D$ & Mean & $S D$ & & \\
\hline Reliving & 5.13 & 1.03 & 5.01 & 0.96 & 0.60 & 0.00 \\
\hline Back in Time & 5.42 & 1.05 & 5.08 & 1.11 & 1.56 & 0.03 \\
\hline $\begin{array}{l}\text { Remember/ } \\
\text { Know** }\end{array}$ & 6.26 & 0.70 & 5.72 & 1.00 & 3.05 & 0.09 \\
\hline Real/Imagine* & 6.57 & 0.62 & 6.25 & 0.84 & 2.12 & 0.05 \\
\hline See & 5.08 & 1.31 & 5.38 & 0.90 & -1.33 & 0.02 \\
\hline Setting & 6.19 & 0.72 & 6.10 & 0.66 & 0.64 & 0.00 \\
\hline Hear** & 5.25 & 1.08 & 4.65 & 1.06 & 2.76 & 0.07 \\
\hline Talk & 4.40 & 1.29 & 4.35 & 1.19 & 0.20 & 0.00 \\
\hline Feel & 4.86 & 1.27 & 5.00 & 1.18 & -0.54 & 0.00 \\
\hline Story & 5.25 & 1.12 & 5.06 & 1.09 & 0.85 & 0.01 \\
\hline Importance** & 4.20 & 1.19 & 3.51 & 1.29 & 2.72 & 0.07 \\
\hline Rehearsal & 3.18 & 0.96 & 3.43 & 1.03 & -1.22 & 0.02 \\
\hline Age at event & 16.04 & 4.20 & 16.95 & 4.97 & -0.96 & 0.01 \\
\hline $\begin{array}{l}\text { Age at earliest } \\
\text { memory }\end{array}$ & 9.10 & 4.71 & 9.44 & 4.64 & -0.35 & 0.00 \\
\hline $\begin{array}{l}\text { Age of most recent } \\
\text { memory* }\end{array}$ & 3.06 & 4.54 & 1.56 & 2.00 & 2.09 & 0.04 \\
\hline
\end{tabular}

$* p<.05 ; * * p<.01$. All other $p$ values were equal to or larger than .12 .

participant. The descriptive statistics as well as results of $t$-tests and effect sizes are presented in Table 2. All $t$-tests were two-tailed.

\section{Metacognitive judgments (recollection and belief)}

As indicated above, recollection was measured by Reliving and Back in Time, and belief by Remember/Know and Real/Imagine.

Neither measure of recollection differed between the groups. However, groups differed on both measures of belief, as can be seen in Table 2: blind participants gave higher Remember/Know as well as Real/Imagine ratings than sighted participants.

\section{Component processes}

The only group difference was in auditory imagery; blind participants reported higher Hear ratings than sighted participants. The difference in visual imagery (See) ratings in favour of the sighted group did not reach significance $(p=.19)$. 


\section{Reported properties of memories}

Blind participants assigned higher importance to their memories than sighted participants. However, there was no difference in the frequency of rehearsal for these memories.

The groups were not different in participants' age-at-event for the memories, with mean age-atevent around 16 for both groups. We also identified each participant's earliest as well as most recent memory. Although there was no difference in terms of the age at earliest memory reported, the most recent memory was older for blind participants than for sighted participants.

In summary, blind participants recalled fewer memories in response to cue words and showed evidence of compensation in terms of imagery reported at the time of retrieval. Despite the fact that the blind participants reported fewer memories, they considered them more important than sighted participants did and reported stronger belief in their memories.

\section{Recent vs. remote memories}

In order to test possible effects of age of memory on the differences we obtained, we divided all memories into two categories as recent vs. remote (childhood) memories. Thus, memories within the most recent 5 years were considered recent, and memories for which the participants were between 6 and 10 years of age were considered to be remote memories. With this classification, there were 25 participants left in the blind group and 27 in the sighted group. Although this meant some loss of participants, these sample sizes are still substantially (two to three times) larger than earlier studies and allow enough power to detect differences.

Relevant data are presented in Figure 1. All the following results are based on 2 (group) $\times 2$ (age of memory) mixed design ANOVAs for each dependent variable.

\section{Metacognitive judgments (recollection and belief)}

There was a main effect of age of memory on all four of the metacognitive ratings, $F s>9.29$, ps < .004 ; ratings for recent memories were higher than those for remote memories. There was a main effect of group for one measure of recollection (Back in Time) and one measure of belief (Remember/Know), Fs > 7.98, ps < .007; blind participants reported higher scores on these dimensions. There was an interaction only for Real/Imagine, $F(1,50)=5.50, M S E=.40, p=$ $.023, \eta^{2}=.10 ;$ sighted participants reported weaker ratings for remote memories than recent ones, $[t(26)=-3.56, p=.001]$, whereas there was no

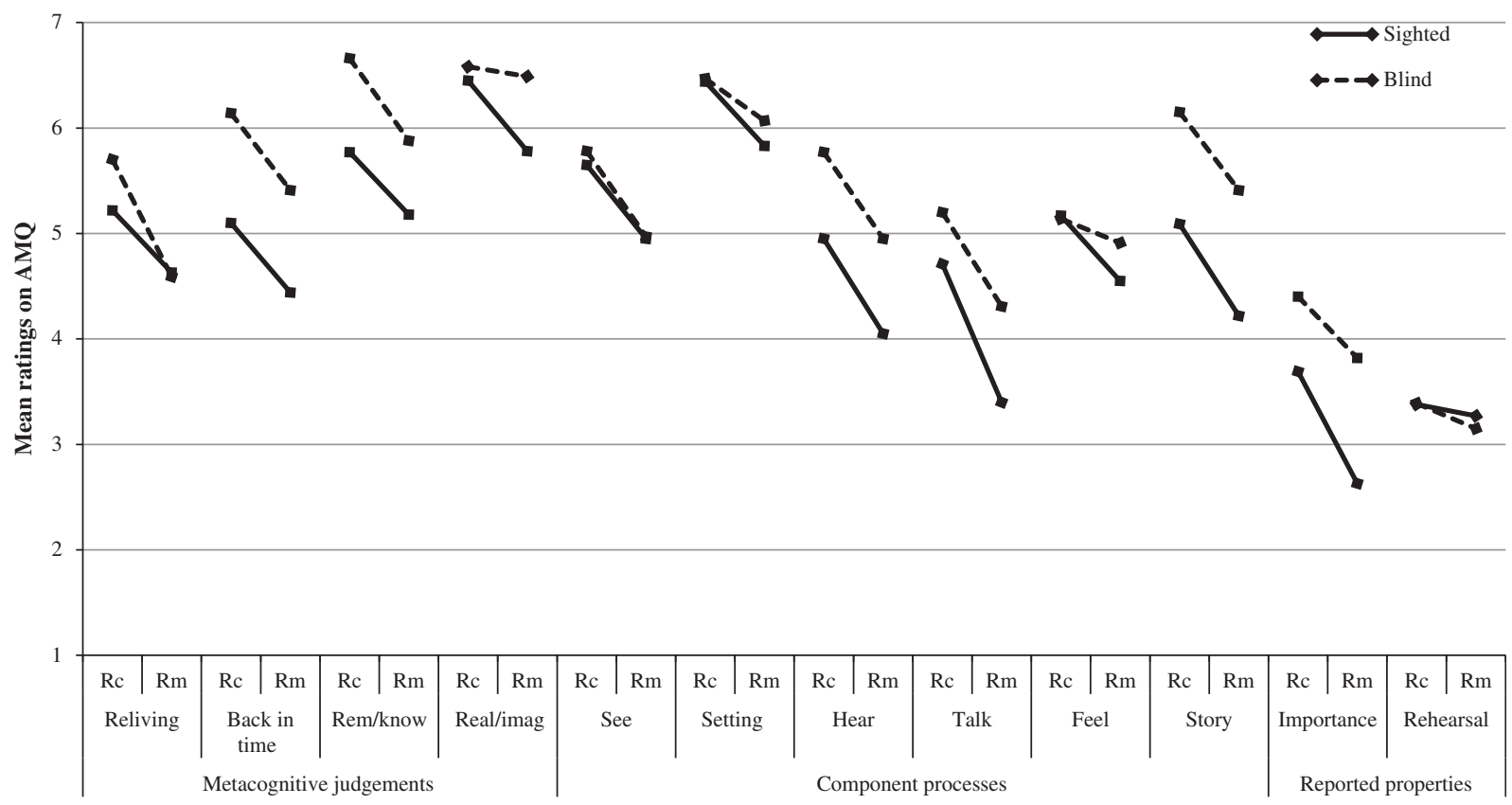

Figure 1. Ratings of variables for recent $(\mathrm{Rc})$ and remote $(\mathrm{Rm})$ memories. 
decline in blind participants' ratings for recent and remote memories, $t(24)<1$.

\section{Component processes}

There was an effect of age of memory for all component processes $(F \mathrm{~s}>8.89, p \mathrm{~s}<.004)$, except Feel, $F(1,50)=2.60, M S E=1.85, p=.113, \eta^{2}=$ .049. As expected, remote memories received lower imagery ratings than the recent ones. There were two group differences: Blind participants reported higher auditory imagery (Hear) than sighted participants, $F(1,50)=7.04, M S E=2.73$, $p=.011, \eta^{2}=.12$. In addition, there was a group difference for narrative (Story), $F(1,50)=14.26$, $M S E=2.30, p<.001, \eta^{2}=.22$, with blind participants reporting higher narrative ratings than sighted participants. There were, however, no interactions $(F \mathrm{~s}<1.09, p \mathrm{~s}>.30)$, indicating that the patterns of imagery ratings were similar for the sighted and blind groups.

\section{Reported properties of memories}

There was an effect of both age of memory $[F(1$, $\left.50)=11.76, M S E=1.50, p=.001, \eta^{2}=.19\right]$ and age of group $[F(1,50)=5.89, M S E=2.00, p=.019$, $\left.\eta^{2}=.11\right]$. There was no interaction. Importance ratings of both groups declined for remote memories, and blind participants gave higher importance ratings than sighted participants for both the recent and remote memories. There was no main effect or an interaction for Rehearsal, $F s<1$.

\section{CONCLUSIONS AND DISCUSSION}

To our knowledge, this is the first study to investigate retrieval, imagery and metacognitive judgments regarding autobiographical memories in blind individuals. We found that blind individuals were able to report fewer word-cued autobiographical memories. They, however, had stronger belief in the accuracy of the memories that they recalled. There was also evidence of compensation in terms of phenomenology, with blind participants reporting stronger narrative and auditory imagery ratings at retrieval. Age of memories (recent vs. remote) had a similar effect on all but one of the variables for blind and sighted participants. We discuss these findings below.

\section{Retrieval success}

The finding that blind participants were less likely to report an autobiographical memory is generally in line with earlier autobiographical memory studies (e.g., Eardley \& Pring, 2006; Goddard \& Pring, 2001, but see Pring \& Goddard, 2004), and may point to the significance of visual imagery in encoding and/or retrieval of autobiographical memories. Although there is clear evidence at the behavioural and neurological levels of recruitment of compensatory processes and reorganisation of the brain in response to congenital/early blindness (e.g., Büchel, Price, \& Friston, 1998; Burton, 2003; Sadato, Okada, Honda, \& Yonekura, 2002), the present findings suggest that such compensation might not help fully in terms of autobiographical memory processes. It is important to note that lack of visual input may be a contributing factor to the observed effect at one of several memory processes (e.g., encoding, retrieval).

Interestingly, this decreased performance in autobiographical memory retrieval is in contrast to the growing number of laboratory episodic memory studies, showing that blind individuals outperform sighted participants. (e.g., Amedi et al., 2003; Pasqualotto et al., 2013; Raz, Striem, Pundak, Orlov, \& Zohary, 2007). One suggestion from these studies is that the visual cortical areas may be recruited to serve, among other functions, episodic memory. Indeed, there is evidence that activation in primary visual cortex during a standard yes/no recognition task for words correlates with accuracy in blind participants (Raz et al., 2005). Obviously, autobiographical memories are more complex and require activation of a wider network of brain areas than typical laboratory memory tasks (Conway et al., 2003; Greenberg et al., 2005; Rubin, 2006). Autobiographical memories entail multi-modal imagery, and arguably, vision is the sense that is most effective in integrating the components of the whole experience not only at the time of encoding but also at the time of repeated rehearsals over the course of one's life. As suggested by Cattaneo and Vecchi (2011), vision may have the added benefit of providing better discrimination of experiences. It is also possible that the advantage of blind individuals in laboratory tasks might be more open to temporary strategic influences. This interesting difference represents a potential for further inquiry. 


\section{Compensation}

Another central finding was that retrieval of autobiographical memories by blind participants was accompanied by an increased auditory imagery and story ratings, compared to sighted participants. This finding as well as the comparable spatial imagery in sighted and blind participants is in line with earlier work (e.g., Ogden \& Barker, 2001). One novel finding from our study was that blind participants reported stronger narrative component than sighted participants at retrieval; in other words, blind participants retrieved autobiographical memories in more of a continuous story-like format rather than discrete moments or images. Therefore, it seems that compensation in blind participants extends to a range of verbal/linguistic/auditory forms.

Interestingly, there was no difference in average visual imagery ratings. It may seem surprising that blind individuals report experiencing visual imagery (measured with the statement "As I remember the event, I see it in my mind") to the same degree as sighted individuals and this brings up the question of whether blind individuals can have visual imagery. First of all, there is a large body of evidence that blind participants show similar patterns to sighted in tasks requiring visuo-spatial imagery, although they may perform lower and/or slower in some of these tasks (e.g., Aleman, van Lee, Mantione, Verkoijen, \& de Haan, 2001; Vecchi, 1998; Vanlierde \& WanetDefalque, 2004; Zimler \& Keenan, 1983). For instance, Aleman et al. (2001) found that blind participants performed accurately in a visual task, where they were given the names of three objects and had to select the odd one out in terms of form. Venlierde and Wanet-Defalque (2004) showed that early-blind participants performed equally well with late-blind and sighted participants on a visuo-spatial imagery task that required creating a mental representation of two-dimensional patterns presented verbally to the participants. Such behavioural effects show that blind individuals generate and report some type of visuo-spatial imagery. Moreover, there is evidence that the visual cortex continues to support mental imagery in blind individuals, such as imagery of objects triggered by sounds of these objects (e.g., De Volder et al., 2001). Although more controversial, some even reported that blind individuals can have visual imagery for colours (Marmor, 1978).
How is it that blind individuals "see" the original experience in their minds? Obviously, the claim is not that visual imagery necessarily indicates pictorial imagery. Indeed, the difference between the sighted and blind participants may not be the end-product (i.e., the subjective experience of seeing) but the underlying process. One likely answer is that mental imagery in blind individuals is analogical (e.g., Vanlierde \& Wanet-Defalque, 2004; Vecchi, Tinti, \& Cornoldi, 2004; Zimler \& Keenan, 1983). As noted by a number of researchers (Cornoldi, De Beni, Giusberti, \& Massironi, 1998; Cattaneo \& Vecchi, 2011), mental images are the result of a generation process, based on other forms of imagery (e.g., auditory) as well as other sources of information such as general knowledge of the world. As such, even representations about visual aspects such as shape of an object can be formed through the recruitment of other modalities such as touch and sound or semantic information about the world (Aleman et al., 2001; Connolly, Gleitman, \& Thompson-Schill, 2007). This sort of a generation process is especially relevant to imagery associated with autobiographical memories, which are complex, multi-modal representations that integrate several sensory modalities, language, emotion, and narrative (Rubin, 2006).

Regardless, though, blind participants reported stronger auditory imagery than sighted participants at retrieval. Importantly, statistical analyses within the blind group comparing totally blind participants $(N=16)$ to those with light perception $(N=24)$ showed that the former group reported stronger auditory imagery $[M s=5.62$ vs. $4.96, t(39)$ $=2.44, p=0.02]$ as well as narrative ratings $[M s=$ 5.54 vs. $4.88, t(39)=2.04, p=.05]$ than the latter group. These findings clearly indicate that degree of visual input moderates compensation at the time of retrieval.

\section{Belief and recollection}

This study was also the first to address belief and recollection associated with autobiographical memories in blind individuals. In the analyses based on all memories, blind participants reported stronger belief in their memories, as measured by Remember/Know and Real/Imagine ratings. When age of memory was included in the analyses, blind participants also reported stronger Back in Time ratings, a measure of recollection. It is difficult to put this finding in context given the paucity of 
research on this topic, except a study by Pring and Painter (2002) who found no difference between the blind and sighted participants in Remember/ Know judgments for words studied in an episodic memory task. We therefore provide a few suggestions, which also integrate the finding that blind participants gave higher importance ratings to their memories.

One possibility is that blind participants might have indeed remembered important memories, and these important memories might be driving the stronger belief and recollection ratings. As noted by Conway (2005), people start, from childhood, to develop memory retrieval models, which "specifies what classes of knowledge have to be combined for a mental representation for a memory" (p. 619). Similar arguments have been put forward emphasising the role of early social interactions in how children learn to talk about memories and what information to include in memories (e.g., Nelson \& Fivush, 2004). It is possible that significance of events may become a more important part of the retrieval model and a stronger marker of memories for blind participants than for sighted participants. Although, to our knowledge, there is no data on this, Eardley and Pring (2006) made a similar point with regard to the role of emotion for blind individuals and suggested that perceived emotional significance of events might help compensate for the lack of visual input. Findings from two studies (Ogden \& Barker, 2001; Pring \& Goddard, 2004), however, did not find a difference in reference to emotions recollections of the past between blind and sighted participants. Another possibility is that retrieval difficulty drives the importance and metacognitive ratings. This is a more attribution-based explanation, suggesting that if blind individuals experience difficulty in accessing memories in general, any successfully retrieved memory might be assigned higher importance and belief ratings as a result of this effort.

\section{Effects of age of memory}

One of the most interesting findings in the present study was the effects of memory age on phenomenological ratings of blind and sighted participants. First, as expected, recent memories were given higher ratings on almost all metacognitive and imagery variables. What is striking is the remarkable consistency in the patterns for blind and sighted participants; age of memory affected all but one variable in the same manner. As noted earlier, several studies found similarities between imagery-related performance of blind and sighted participants in tasks such as mental rotation or mental scanning (e.g., Kerr, 1983; Vanlierde \& Wanet-Defalque, 2004). These studies found differences between the sighted and blind participants in overall performance or speed, but performance of both groups in mental imagery tasks was influenced in the same way by variables such as occlusion or object size (Kerr, 1983). Our findings suggest that the processes underlying autobiographical memory phenomenology operate similarly in the blind and sighted participants.

One limitation of the present study was that tactile imagery was not measured as it is a modality mentioned by the blind participants when they talk about past experiences (e.g., Ogden and Barker, 2001). Therefore, it is an imagery modality which would be expected to differ between the two groups and provide further information about the compensation, we do not think that this omission would have influenced the results reported regarding other measures.

In summary, we found several differences in terms of retrieval and phenomenology of autobiographical memories between the blind and sighted participants, along with a remarkable similarity in how these variables were influenced by the age of memories. Some of our findings (e.g., stronger belief in blind participants) point to particularly interesting questions for further inquiry and indicate the potentially important role of studying autobiographical memory in visual impairment.

\section{REFERENCES}

Alary, F., Duquette, M., Goldstein, R., Elaine Chapman, C., Voss, P., La Buissonnière-Ariza, V., \& Lepore, F. (2009). Tactile acuity in the blind: A closer look reveals superiority over the sighted in some but not all cutaneous tasks. Neuropsychologia, 47, 2037-2043. doi:10.1016/j.neuropsychologia.2009. 03.014

Aleman, A., van Lee, L., Mantione, M. H. M., Verkoijen, I. G., \& de Haan, E. H. F. (2001). Visual imagery without visual experience: Evidence from congenitally totally blind people. Neuroreport, 12, 2601-2604. doi:10.1097/00001756-200108080-00061

Amedi, A., Raz, N., Pianka, P., Malach, R., \& Zohary, E. (2003). Early 'visual' cortex activation correlates with superior verbal memory performance in the blind. Nature Neuroscience, 6, 758-766. doi:10.1038/ nn1072

Brewer, W. F. (1986). What is autobiographical memory? In D. C. Rubin (Ed.), Autobiographical memory 
(pp. 25-49). New York, NY: Cambridge University Press.

Brewer, W. F. (1996). What is recollective memory? In D. C. Rubin (Ed.), Remembering our past: Studies in autobiographical memory (pp. 19-66). Cambridge: Cambridge University Press.

Büchel, C., Price, C., \& Friston, K. (1998). A multimodal language region in the ventral visual pathway. Nature, 394, 274-277. doi:10.1038/28389

Burton, H. (2003). Visual cortex activity in early and late blind people. The Journal of Neuroscience, 23, 4005-4011.

Cattaneo, Z., \& Vecchi, A. (2011). Blind vision: The neuroscience of visual impairment. Cambridge: MIT Press.

Connolly, A. C., Gleitman, L. R., \& Thompson-Schill, S. L. (2007). Effect of congenital blindness on the semantic representation of some everyday concepts. Proceedings of the National Academy of Sciences, 104, 8241-8246. doi:10.1073/pnas.0702812104

Conway, M. A. (2005). Memory and the self. Journal of Memory and Language, 53, 594-628. doi:10.1016/j. jml.2005.08.005

Conway, M. A., \& Pleydell-Pearce C. W. (2000). The construction of autobiographical memories in the self-memory system. Psychological Review, 107, 261-288. doi:10.1037/0033-295X.107.2.261

Conway, M. A., Pleydell-Pearce, C. W., \& Whitecross, S. E. (2001). The neuroanatomy of autobiographical memory: A slow cortical potential study of autobiographical memory retrieval. Journal of Memory and Language, 45, 493-524. doi:10.1006/jmla.2001.2781

Conway, M. A., Pleydell-Pearce, C. W., Whitecross, S. E., \& Sharpe, H. (2003). Neurophysiological correlates of memory for experienced and imagined events. Neuropsychologia, 41, 334-340. doi:10.1016/ S0028-3932(02)00165-3

Cornoldi, C., De Beni, R., Giusberti, F., \& Massironi, M. (1998). Memory and imagery: A visual trace is not a mental image. In M. A. Conway, S. Gathercole, \& C. Cornoldi (Eds.), Theories of memory (pp. 87110). Hove: Psychology Press.

De Volder, A. G., Toyama, H., Kimura, Y., Kiyosawa, M., Nakano, H., Vanlierde, A. ... Senda, M. (2001). Auditory triggered mental imagery of shape involves visual association areas in early blind humans. Neuroimage, 14(1), 129-139. doi:10.1006/nimg.2001.0782

Eardley, A. F., \& Pring, L. (2006). Remembering the past and imagining the future: A role for nonvisual imagery in the everyday cognition of blind and sighted people. Memory, 14, 925-936. doi:10.1080/ 09658210600859582

Ely, R., \& Mercurio, A. (2011). Time perspective and autobiographical memory: Individual and gender differences in experiencing time and remembering the past. Time \& Society, 20, 375-400. doi:10.1177/ 0961463X10366081

Goddard, L., \& Pring, L. (2001). Autobiographical memory in the visually impaired: Initial findings and impressions. British Journal of Visual Impairment, 19(3), 108-113. doi:10.1177/026461960101900306

Göz, İ. (2003). Yazılı türkçenin kelime sıklığı sözlüğü [Word frequency dictionary of written Turkish]. Ankara: Türk Dil Kurumu.
Greenberg, D. L., Eacott, M. J., Brechin, D., \& Rubin, D. C. (2005). Visual memory loss and autobiographical amnesia: A case study. Neuropsyhologia, 43, 14931502. doi:10.1016/j.neuropsychologia.2004.12.009

Greenberg, D., \& Rubin, D. (2003). The neuropsychology of autobiographical memory. Cortex, 39, 687728. doi:10.1016/S0010-9452(08)70860-8

Kerr, N. H. (1983). The role of vision in visual imagery experiments: Evidence from the congenitally blind. Journal of Experimental Psychology: General, 112, 265-277. doi:10.1037/0096-3445.112.2.265

Lessard, N., Pare, M., Lepore, F., \& Lassonde, M. (1998). Early-blind human subjects localize sound sources better than sighted subjects. Nature, 395, 278-280. doi:10.1038/26228

Marmor, G. S. (1978). Age at onset of blindness and the development of the semantics of color names. Journal of Experimental Child Psychology, 25, 267-278. doi:10.1016/0022-0965(78)90082-6

Nelson, K., \& Fivush, R. (2004). The emergence of autobiographical memory: A social cultural developmental theory. Psychological Review, 111, 486-511. doi:10.1037/0033-295X.111.2.486

Ogden, J. A. (1993). Visual object agnosia, prosopagnosia, achromatopsia, loss of visual imagery and autobiographical amnesia following recovery from cortical blindness: Case M. H. Neuropsychologia, 31, 571-589. doi:10.1016/0028-3932(93)90053-3

Ogden, J. A., \& Barker, K. (2001). Imagery used in autobiographical recall in early and late blind adults. Journal of Mental Imagery, 25, 153-176.

Pasqualotto, A., Lam, J. S. Y., \& Proulx, M. J. (2013). Congenital blindness improves semantic and episodic memory. Behavioural Brain Research, 244, 162-165. doi:10.1016/j.bbr.2013.02.005

Postma, A., Zuidhoek, S., Noordzij, M. L., \& Kappers, A. M. L. (2007). Differences between early blind, late blind and blindfolded sighted people in haptic spatial configuration learning and resulting memory traces. Perception, 36, 1253-1265. doi:10.1068/p5441

Pring, L., \& Goddard, L. (2004). Autobiographical memory: Insights from individuals with a visual impairment. In S. Ballesteros \& M. A. Heller (Eds.), Touch, blindness and neuroscience (pp. 55-62). Madrid: UNED, Varia.

Pring, L., \& Painter, J. (2002). Recollective experience in individuals with a visual impairment: The role of sensory and conceptual processing. British Journal of Visual Impairment, 20(1), 24-32. doi:10.1177/026461 960202000105

Raz, N., Amedi, A., \& Zohary, E. (2005). V1 activation in congenitally blind humans is associated with episodic retrieval. Cerebral Cortex, 15, 1459-1468. doi:10.1093/cercor/bhi026

Raz, N., Striem, E., Pundak, G., Orlov, T., \& Zohary, E. (2007). Superior serial memory in the blind: A case of cognitive compensatory adjustment. Current Biology, 17, 1129-1133. doi:10.1016/j.cub.2007.05.060

Röder, B., Rösler, F., \& Spence, C. (2004). Early vision impairs tactile perception in the blind. Current Biology, 14, 121-124.

Rokem, A., \& Ahissar, M. (2009). Interactions of cognitive and auditory abilities in congenitally blind individuals. Neuropsychologia , 47, 843-848. doi:10.10 16/j.neuropsychologia.2008.12.017 
Rubin, D. C. (1995). Introduction. In D. C. Rubin (Ed.), Remembering our past: Studies in autobiographical memory (pp. 1-15). New York, NY: Cambridge University Press.

Rubin, D. C. (2005). A basic-systems approach to autobiographical memory. Current Directions in Psychological Science, 14(2), 79-83. doi:10.1111/j.09637214.2005.00339.x

Rubin, D. C. (2006). The basic-systems model of episodic memory. Perspectives on Psychological Science, 1, 277-311. doi:10.1111/j.1745-6916.2006.00017.x

Rubin, D. C., Boals, A., \& Berntsen, D. (2008). Memory in posttraumatic stress disorder: Properties of voluntary and involuntary, traumatic and non-traumatic autobiographical memories in people with and without PTSD symptoms. Journal of Experimental Psychology: General, 137, 591-614. doi:10.1037/a0013165

Rubin, D. C., Burt, C. D. B., \& Fifield, S. J. (2003). Experimental manipulations of the phenomenology of memory. Memory \& Cognition, 31, 877-886. doi:10.3758/BF03196442

Rubin, D. C., \& Greenberg, D. L. (1998). Visual memory-deficit amnesia: A distinct amnesic presentation and etiology. Proceedings of the National Academy of Sciences of the USA, 95, 5413-5416. doi:10.1073/pnas.95.9.5413

Rubin, D. C., \& Kozin, M. (1984). Vivid memories. Cognition, 16(1), 81-95. doi:10.1016/0010-0277(84) 90037-4

Rubin, D. C., Schrauf, R. W., \& Greenberg, D. L. (2003). Belief and recollection of autobiographical memories. Memory \& Cognition, 31, 887-901. doi:10.3758/BF03196443

Rubin, D. C., Schrauf, R. W., Gulgoz, S., \& Naka, M. (2007). On the cross-cultural variability of component processes in autobiographical remembering: Japan, Turkey, and the USA. Memory, 15, 536-547. doi:10.1080/09658210701332679

Rubin, D. C., \& Siegler, I. C. (2004). Facets of personality and the phenomenology of autobiographical memory. Applied Cognitive Psychology, 18, 913930. doi:10.1002/acp.1038

Saariluoma, P., \& Kalakoski, V. (1998). Apperception and imagery in blindfold chess. Memory, 6(1), 67-90. doi:10.1080/741941600
Sadato, N., Okada, T., Honda, M., \& Yonekura, Y. (2002). Critical period for cross-modal plasticity in blind humans: A functional MRI study. Neuroimage, 16(2), 389-400. doi:10.1006/nimg.2002.1111

Sheen, M., Kemp, S., \& Rubin, D. (2001). Twins dispute memory ownership: A new false memory phenomenon. Memory \& Cognition, 29, 779-788. doi:10.3758/ BF03196407

Svoboda, E., McKinnon, M. C., \& Levine, B. (2006). The functional neuroanatomy of autobiographical memory: A meta-analysis. Neuropsychologia, 44, 21892208. doi:10.1016/j.neuropsychologia.2006.05.023

Talarico, J. M., LaBar, K. S., \& Rubin, D. C. (2004). Emotional intensity predicts autobiographical memory experience. Memory \& Cognition, 32, 1118-1132. doi:10.3758/BF03196886

Thaler, L., Arnott, S. R., \& Goodale, M. A. (2011). Neural correlates of natural human echolocation in early and late blind echolocation experts. PLoS One, 6, e20162. doi:10.1371/journal.pone.0020162.s026

Tinti, C., Galati, D., Vecchio, M. G., De Beni, R., \& Cornoldi, C. (1999). Interactive auditory and visual images in persons who are totally blind. Journal of Visual Impairment \& Blindness, 93, 579-583.

Williams, J. M. G., Healy, H. G., \& Ellis, N. C. (1999). The effect of imageability and predicability of cues in autobiographical memory. The Quarterly Journal of Experimental Psychology, 52, 555-579.

Vanlierde, A., \& Wanet-Defalque, M.-C. (2004). Abilities and strategies of blind and sighted subjects in visuo-spatial imagery. Acta Psychologica, 116, 205222. doi:10.1016/j.actpsy.2004.03.001

Vecchi, T. (1998). Visuo-spatial imagery in congenitally totally blind people. Memory, 6(1), 91-102. doi:10.10 80/741941601

Vecchi, T., Tinti, C., \& Cornoldi, C. (2004). Spatial memory and integration processes in congenital blindness. NeuroReport, 15, 2787-2790.

Zimler, J., \& Keenan, J. M. (1983). Imagery in the congenitally blind: How visual are visual images? Journal of Experimental Psychology: Learning, Memory, and Cognition, 9, 269-282. doi:10.1037/02787393.9.2.269 